\title{
s- \\ Experiences with Mechatronics Education at the University of Twente
}

\author{
Job van Amerongen \\ Drebbel Institute for Mechatronics and Department of Electrical Engineering, University of Twente \\ P.O. Box 217, 7500 AE Enschede, Netherlands \\ J.vanAmerongen@utwente.nl
}

\begin{abstract}
This paper describes the experiences with a number of variants of mechatronic programmes offered by the University of Twente since 1989. Mechatronics education took place in a two-year Mechatronic Designer programme, in specialisations in Electrical and Mechanical Engineering and in an international MSc programme. In the new European $\mathrm{BSc} / \mathrm{MSc}$ structure the University of Twente will offer an MSc Mechatronics where the course language will be English. There have been large mechatronic projects, where $4 \mathrm{PhD}$ and some 50 MSc students did their thesis work as well as two-week Mechatronic projects in the BSc curricula of EE and ME. The Iatter show that mechatronics is not only a topic of interest for students who want to specialise in this direction, but that mechatronic projects also offer a challenge for electrical and mechanical engineering students in general.
\end{abstract}

\section{Introduction}

There are several mechatronic programmes offered at universities worldwide. These programmes range from complete programmes to shorter programmes, following a $\mathrm{BSc}$ or even an MSc programme. Also mechatronic components have been introduced in Electrical and Mechanical Engineering programmes. Mechatronic projects are in general considered as motivating elements of a study programme, also for students who are more interested in other topics. This paper describes the experiences with a number of variants of mechatronic programmes offered by the University of Twente in the last 15 years in relation to the research in the Drebbel Institute for Mechatronics.

\subsection{Context}

The University of Twente started in 1964. In the first years of the university all departments shared a common first year that provided a broad programme to all engineering students. Even after this general first year was abounded, it was common practice to have a representative of another department in the committee that guided and finally judged the thesis work of students. This close cooperation between staff members of the various departments led to a good knowledge of each others activities and a lot of interaction. It has been the basis for many multi- and interdisciplinary research activities, now concentrated in a number of research institutes that have their activities over the borders of the more mono-disciplinary faculties and departments.
In 1989, after obtaining $M € 1,25$ of extra funding from the Ministry of Education, 5 groups in the faculties of Electrical Engineering, Mechanical Engineering, Applied Mathematics and Computer Science started cooperation in the Mechatronics Research Centre Twente (MRCT). The MRCT started a large research project (the MART project, discussed in Section 1.1.1) involving $4 \mathrm{PhD}$ students and many MSc students. The 2 year post-graduate Mechatronic Designer programme was started and a part-time professor in Mechatronics with a lot of industrial experience in Philips Centre for Industrial Technology was appointed in the Faculties of Electrical and Mechanical Engineering. The Mechatronic Designer programme is further discussed in Section 2. In 1998 the MRCT got a more formal status in the form of the Drebbel Research Institute for Mechatronics. Because of changes in the educational system in the Netherlands the Mechatronic Designer programme has disappeared and for some time mechatronics was a specialisation in the MSc programmes of the faculties of EE and ME. Since 2001 the University of Twente offers a two-year international MSc programme in Mechatronics. In 2001 the University of Twente transformed its study programmes to the new European $\mathrm{BSc} / \mathrm{MSc}$ structure. This implies that the MSc programmes will start in September 2004 when the first generation of BSc students will have completed their BSc. One of the programmes will be a new MSc Mechatronics. The course language will be English. The present international MSc programme will merge with this new MSc Mechatronics programme.

Good academic education in advanced topics is only possible when this is supported by research programmes. Therefore, a short description will be given of some of the research projects and topics of the Drebbel Institute.

\subsubsection{MART project}

One of the first attempts to run a number of $\mathrm{PhD}$ and $\mathrm{MSc}$ projects with a large mechatronics content was a project started in 1990 . The idea was to build an advanced mobile robot that should be able to gather components from partsupply stations and assemble these components while driving around in a factory. Apart from the aspect of being an attractive solution for flexibly building many variants of a product or a variety of products, the goal of this project was to learn and demonstrate a mechatronics approach in an interdisciplinary project. In a period of about 5 years, $4 \mathrm{PhD}$ and approximately $50 \mathrm{MSc}$ students did their thesis work in this project. Students from electrical engineering, mechanical engineering and computer science worked together in one project room. 
This alone has contributed to learning students with a basic education in their own field the language from other disciplines and to work together in a project with a clear systems approach. This means that not the best solution for an isolated problem could be sought, but that the consequences for other parts of the design and for the systems as a whole had to be taken into account all the time. As a result the mobile robot was completely realised (Fig. 1). It had many advanced features in the field of mechanical constructions [13] and control such as an adaptive preload system to reduce friction and backlash [10], learning control [14], parallel computing, autonomous navigation [12], [8] etc. Even more important is that for many of the students working in this project this experience has been the start of a successful career in mechatronics. More about the technical details of this project can be found in [2]. A video is available at the web [18].

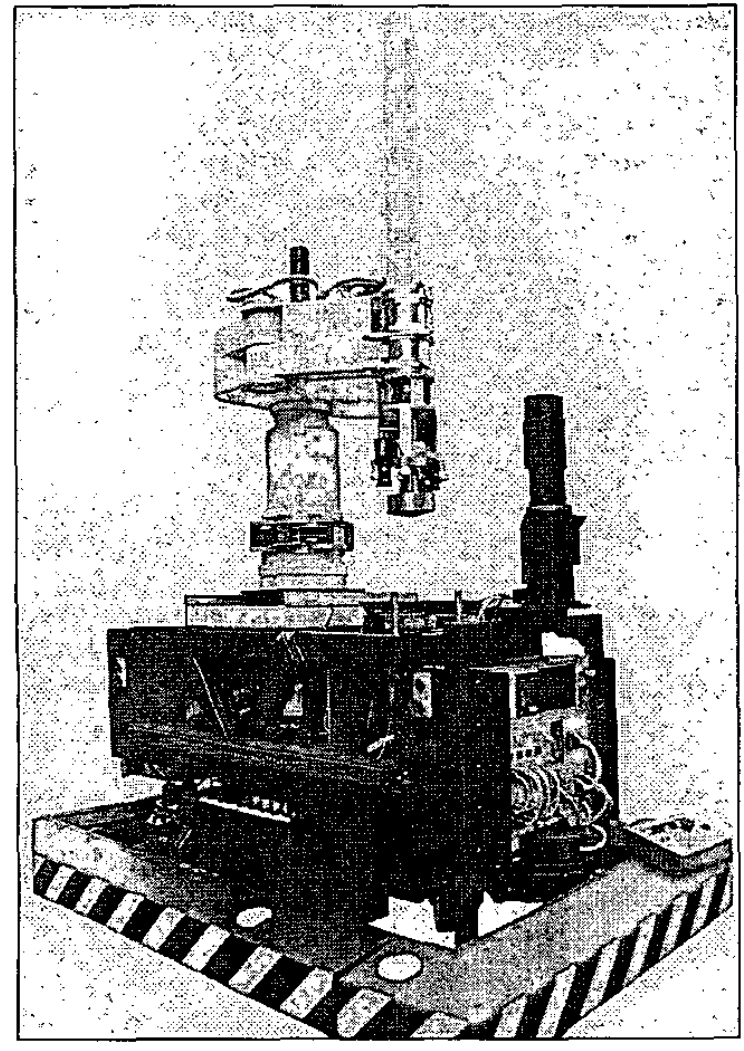

Fig. 1 MART robot after completion

\subsubsection{Other research topics}

Several other research topics, mostly related to $\mathrm{PhD}$ research provide an environment for smaller and larger student projects. The research of the groups that are responsible for this MSc programme concentrates on the following topics:

- Modelling and simulation of mechatronic systems

- Vibration Control (active damping)

- Learning Feed-forward control
- Embedded Control Systems

- Mechatronic Measurement Systems

- Laser welding and surface treatment with robots

All this work is related to mechatronic design. Mechatronic design can be defined as the integrated and optimal design of a mechanical system and its embedded control system. The mechatronic design philosophy is made explicit in the approach to modelling and simulation of mechatronic systems. By using a port-based approach elements from various domains can easily be modelled. Because the physical parameters are maintained in the modelling process, modifications in the mechanical, electrical or controller domain can easily be evaluated, allowing for a true mechatronic design approach [3]. One of the results of this work is the modelling and simulation programme 20-sim [15]. Based on the research of the Control Engineering Group, this programme is now commercially available from a spin-off company. Models can be described in the form of ideal physical models and be represented by icons or bond graphs. They can be simulated or transferred into transfer functions or statespace descriptions and used in typical controller design tools such as root loci or bode plots. In the state-space models the physical parameters are maintained. A typical example of these physical models is given in Fig. 2 . The same servo system is shown in the form of iconic diagrams and as a bond graph. The models of the physical parts can easily be combined with controller elements. This leads to structures as given in Fig. 3. In Fig. 3 the elements of Fig. 2 have been combined into higher level sub models. More information of this approach can be found in [3], [4], [6].

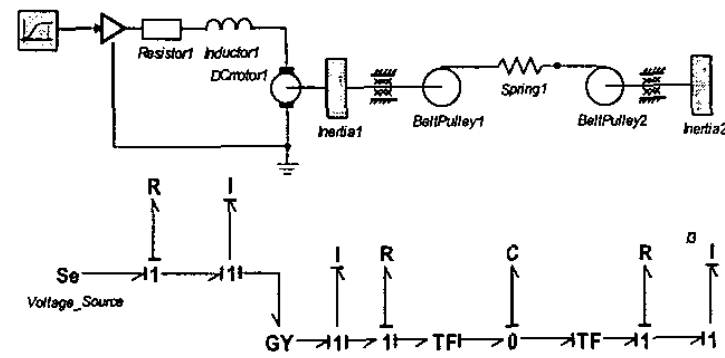

Fig. 2 20-sim model of a servo system

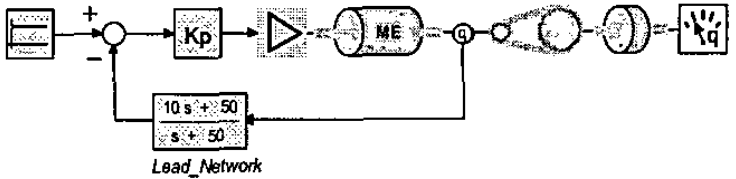

Fig. 3 Controlled servo system

\subsection{Basic philosophy}

One could argue whether it would be better to complete a basic education in $\mathrm{ME}$ or $\mathrm{EE}$, followed by additional mechatronics education, or that a coherent mechatronics programme is desirable. The philosophy at the University of Twente has always been that a good basis in one of the 
basic disciplines is desirable. Providing the missing information in a second phase will help to bring the ME or $\mathrm{EE}$ at the level of a valuable partner in a mechatronic design team. In other words, the specialised monodisciplinary education in traditional EE or ME curricula has to be widened and some basic knowledge of the other discipline should be taught to mechatronic engineers. Without extending the programme, this goes at the expense of a little bit less deep knowledge of the own discipline. This is indicated in Fig. 4. The originally, more narrow, $\mathrm{EE}$ and $\mathrm{ME}$ programmes are made broader, leading to a mechatronic engineer, who still has clearly distinguishable roots in either $\mathrm{EE}$ or ME.

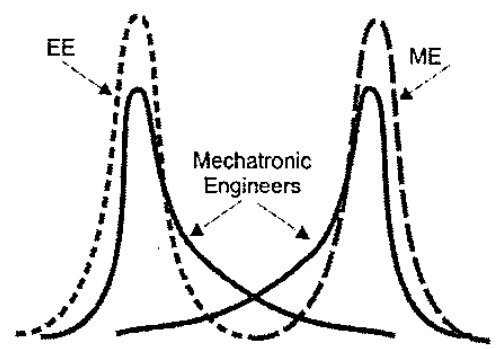

Fig. 4 Mechatronic engineers versus conventional mono-disciplinary EE's and ME's

\section{The Mechatronic Designer Programme}

Traditionally the academic engineering education in the Netherlands consisted of a programme of five years leading to an MSc degree. During a number of years a four year programme was offered with the idea that $60 \%$ of the graduates would go to industry after these four years. The other $40 \%$ were supposed to follow an additional two year designer programme or a four year $\mathrm{PhD}$ programme. During this period a Mechatronic Designer programme was offered by the University of Twente, later followed by the other two Dutch technical universities [1]. This programme consisted of one year of courses and a one year design project. The courses were intended to teach graduates from mechanical engineering some essential topics from EE and electrical engineering graduates some essentials from ME. In addition, a number of advanced courses were offered to deepen the knowledge in topics relevant for mechatronics, including some non-technical courses. The second year was completely filled with a design project, preferably with an industrial partner. Only the better students were admitted to this programme. Many interesting projects were carried out in this period. The projects with industry clearly demonstrated that the graduates of this programme were indeed able to get impressive results with sometimes complex mechatronic projects.

As an example the ALASCA project could be mentioned [2]. Three students of the Mechatronic Designer programme (one with an $\mathrm{EE}$ and two with an $\mathrm{ME}$ background) worked on the design of a system that should be able to place IC's (Surface Mounted Devices or SMD's) on a printed circuit board at high speed and accuracy. After placing the SMD, its leads were welded by means of a laser beam. This project was done in cooperation with one of the Philips factories involved in the construction of fast component mounting machines and based on the specifications of a new generation of machines. The project involved the design of an energyefficient $A C$ servo system that was able to rotate and translate simultaneously, including a newly developed optical sensor that generated resolver-like signals. This patented device enabled, by means of a standard resolverto-digital converter, angle measurement with 14 bits accuracy. The laser welding part of the project involved the design and construction of an accurate positioning system for moving the laser beam and research related to the process parameters (intensity, duration and angle of incidence of the laser spot). As a result the AC-servo manipulator as well as the laser welding system were successfully built and demonstrated. The laser welding system could make 30 welds per second. A video of the project is available [19].

The high quality of the projects in this programme can also be contributed to the fact that only the best students were admitted in a rigorous selection procedure. Despite the success of the Mechatronic Designer programme, it has stopped for probably two main reasons:

- The educational system changed from a four year programme to a five year program again. The need for extra time at the university, other than for a $\mathrm{PhD}$, was less obvious for most students

- The good economy led to a high demand of graduates from the MSc programme, making the less-paid two-year Mechatronic Designer programme less attractive.

Another reason of the suddenly decreased interest in all designer programmes in the Netherlands is probably that the compulsory military service was abolished. In the years before graduates had an easy choice: 'spoil' one and a half year as an involuntary soldier or go for extra education in one of the designer programmes.

\section{Specialisations in EE and ME}

When the Mechatronic Designer programme stopped mechatronic thesis projects continued, especially for $\mathrm{EE}$ and $\mathrm{ME}$ students as specialisations in the programmes of the departments of ME and EE. Because in these cases the thesis work is only 25 weeks and because less elective courses can be followed in another discipline, the graduates from these specialisations certainly had less mechatronic skills than those from the designer programme. Of course the more research-oriented $\mathrm{PhD}$ programmes continued.

\section{MSc Mechatronics}

Since 2001 the University of Twente offers an international MSc programme Mechatronics. This two year programme is taught in English. Candidates from good higher education institutes world wide are admitted after a rigorous selection. This programme anticipated on the European $\mathrm{BSc} / \mathrm{MSc}$ structure which offers new 
possibilities for a proper Mechatronics programme. The University of Twente successfully applied for a license to offer an MSc in Mechatronics [16]. Because all courses will be taught in English the international programme will be incorporated in the new MSc programme on Mechatronics. The programme will consist of the following elements:

- removing deficiencies

- homologising phase

- courses to deepen the knowledge

- elective courses

- thesis project

The programme is tailored for each individual student. The first year starts with the homologising phase (1 trimester) where deficiencies for the Mechatronics programme are being removed. This means, for instance, that students with an EE BSc follow Mechanical Engineering courses and students with an $\mathrm{ME} \mathrm{BSc}$ follow Electrical Engineering courses. For graduates from polytechnics an extra trimester is compulsory, mainly filled with mathematics courses. The second trimester is filled with compulsory courses such as:

- digital control

- introduction to system identification

- measurement systems for mechatronics

- mechatronics

- advanced motion control

- embedded control systems

The last trimester of the first year is filled with elective courses. For students with an undergraduate education at a Dutch university, the second year starts with one trimester of industrial training, preferably abroad. The others can follow additional courses to remove any deficiencies in their knowledge or choose from the electives. The last two trimesters are filled with the thesis project in one of the ongoing mechatronic research projects in the participating groups. Reactions from international MSc students on this programme have been enthusiastic so far [17].

\section{Mechatronic projects in the curriculum}

Mechatronic projects are stimulating for students in electrical as well as in mechanical engineering [7]. As an example a description will be given of the mechatronics project of the EE BSc programme. The second trimester of the second year is filled with courses like: mechanics and transduction technology, measurements, modelling and simulation of dynamical systems, control engineering and linear systems. In order to integrate the more theoretical knowledge taught in these courses there is a two-week project at the end of the trimester. Students work in teams of four. Each team is provided with "a transducer" and is asked to build a mechatronic system with this transducer. In many cases the transducers can be used both as a sensor and actuator. They may use all kinds of other construction material available (e.g. Lego or meccano) as well as other sensors and actuators. They get a small amount of money to buy other mechanical or electronic components, not standard available. For each team standard measurement equipment such as a multi-meter, oscilloscope and signal generator are available as well as a PC with Labview. On the $P C$ they can run the modelling and simulation package $20-\operatorname{sim}$ [15] as well as word processing software for reporting. 20-sim can be used for analysis of the system design, for controller design as well as for automatic generation of $\mathrm{C}$ code for the digital controller that may be necessary in the systems. The controller code can be downloaded into a DSP board that is available for each team to test the digital controller. The project starts with an introduction at the Friday before the full two weeks of the project. After two days a plan has to be delivered that is judged by the supervisors (teaching assistants and staff from the various groups involved in the project). After approval of the plan a more detailed plan, including simulations and detailed characterisation of the components in the set up to be build has to be completed. At the end of the first week this plan is judged again by the supervisors and only after approval of this plan the construction of the various parts of the system may start. Students like the project and sometimes impressive setups are being realized. A few impressions are given in the pictures of Fig. 5 and Fig. 6. Also in ME a mechatronics project is carried out.

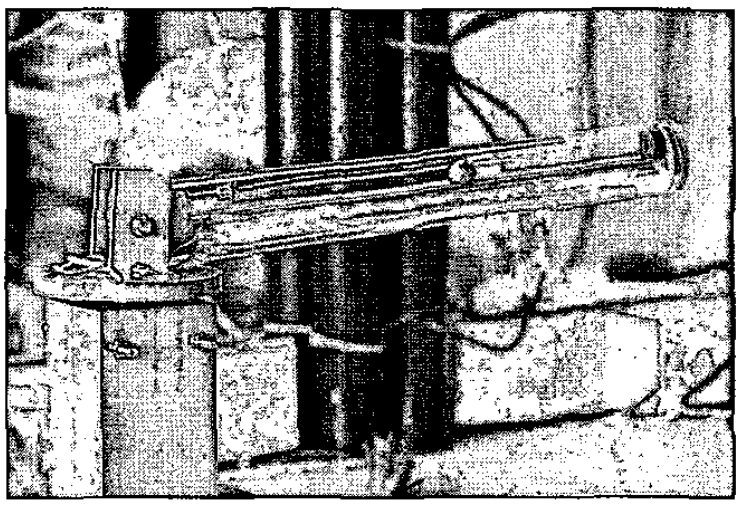

Fig. 5 One of the set ups

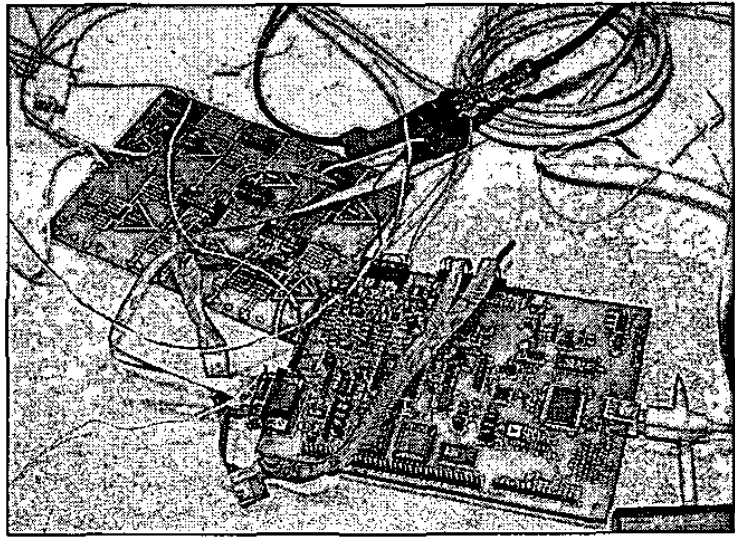

Fig. 6 DSP board and analogue board for circuits with operational amplifiers 


\section{Conclusions}

An overview has been given of the experiences with several variants of mechatronic programmes in the University of Twente. External factors influence the attractiveness of such programmes. Participating in the Mechatronic Designer programme enabled students to escape the military service that was going to be abounded. During a number of years this attracted many students. Also the economic situation and the idea students have about the completeness of their education determine whether it is attractive to spend extra years at the university. The changes in these external factors have led to the discontinuation of the further successful Mechatronic Designer programme.

The new BSc/MSc structure has enabled the University of Twente to define a new MSc programme in Mechatronics. So far the industry is enthusiastic about the results of our educational programmes. A conglomerate of regional mechatronic companies have organised themselves in 'Mechatronics Valley Twente'. They have taken the initiative of offering the University of Twente a part time professor in Mechatronic Design. Presently this position is filled by a professor with a lot of industrial experience within the Philips Centre for Industrial Technology. The experiences so far and the new MSc programme will help in producing the urgently needed Mechatronic Engineers. Several companies near the university are directly the result of the mechatronic activities in the University of Twente. The project leader of the MART project (see Section 1.1.1) is now director of the successful mechatronic engineering company DEMCON. One of the Mechatronic Designer students in the ALASCA project is the chief designer in this company. Through the Interreg III programme, the EU sponsors the Dutch German Euregio Mechatronic Innovation Centre. This centre provides support on mechatronic design to small and medium-sized companies (SME's) in the Euregio, the border region of the Netherlands and Germany. Because of the cooperation of the University of Twente and the Fachhochschule Gelsenkirchen in Bocholt, not only research-oriented, but also more development-oriented questions from the industry can be answered. One of the ways to help the SME's is by means of short courses in topics relevant for mechatronic design. Also post doctoral courses for engineers in industry on topics like 'Construction Principles' and 'Mechatronic Design' have proven to answer a need of the industry

\section{References}

[1] Amerongen, J. van and W. Jongkind, "Mechatronics in the Netherlands", IEEE/ASME Transactions on Mechatronics, Vol. 1, no. 2, pp. 106-110, 1996.

[2] Amerongen J. van, M.P. Koster, "Mechatronics at the University of Twente" in Proceedings American Control Conference (AAC), Albuquerque, New Mexico, U.S.A, pp 2972-2976, ISBN 0-7803-3832-4, 1997

[3] Amerongen, J. van, "The Mechatronics Handbook: The Role of Controls in Mechatronics", in: The
Mechatronics Handbook, CRC Press, Boca Raton (FA), USA, Robert H. Bishop, ed., pp 21.1-21.17, ISBN 08493 00665, 2002

[4] Amerongen, J. van and P.C. Breedveld, "Modelling of Physical Systems for the Design and Control of Mechatronic Systems (IFAC Professional Brief)".in: Annual Reviews in Control 27, Elsevier Ltd., pp 87117, S1367-5788, 2003. Also available at: http://www.oeaw.ac.at/ifac/publications/pbriefs/PB Modelling of Physical Systems final.pdf

[5] Blömers, T.G. and P.T. Rutgers, Design and implementation of a $z-\varphi$ controlled pipette, Report mechatronic design course, Control Laboratory, Dept. of EE, University of Twente, 1993

[6] Breedveld, P.C., "Port-Based Modeling of Mechatronic Systems", in: 4th IMACS Symposium on Mathematical Modelling, Vienna University of Technology, Austria, pp 1-20, ISBN 3-901608-24-9, 2003

[7] Craig, K, and Stolfi, F, Teaching Control System Design through Mechatronics: Academic and Industrial Perspectives, Proceedings of the 7th Mechatronics Forum International Conference, Atlanta, Georgia, USA, ISBN 008043703 6, 2000

[8] Graaf, A.J. de, On-line measuring systems for a mobile vehicle and a manipulator gripper, PhD.Thesis, University of Twente, 1994

[9] Jovanovic, D. S., B. Orlic, J. Broenink, J. van Amerongen, "Inexpensive Prototyping Environment for Mechatronic Systems", in: Proceedings WESIC 2003, Miskolc, HUNGARY May 28-30 2003

[10] Kruijer, C.W., Geregeld voorspannen van tandwielen, MSc thesis, University of Twente, 1992 (in Dutch)

[11] Oelen, W. Modelling as a tool for design of mechatronic systems, PhD.-Thesis, University of Twente, 1995

[12] Oelen, W. and J. van Amerongen, Robust Tracking Control of Two Degrees of Freedom Mobile Robots, Control Engineering Practice, Vol. 2, No. 2, April 1994, pp. 333-340, 1994

[13] Schipper, D.A., Mobile Autonomous Robot Twente - a mechatronics design approach, $\mathrm{PhD}$.-Thesis, University of Twente, pp. 155, ISBN 9036516862, 2001

[14] Starrenburg, J.G., W.T.C. van Luenen, W. Oelen and $\mathrm{J}$. Van Amerongen, Learning Feed forward Controller for a Mobile Robot Vehicle, Control Engineering Practice, Vol. 4, No. 9, pp. 1221-1230

[15] http://www.20sim.com

[16] http://www.ce.utwente.nl/MSc mechatronics/

[17] http://www.ce.utwente.nl/MSc_mechatronics/Impress ions/index.htm

[18] mms:/video.utwente.nl/Control Engineering/MART. wmv

[19] mms://video.utwente.n//Control_Engineering/ALASC A.wmv 